\title{
Divided attention and indirect memory tests
}

\author{
NEIL W. MULLIGAN and MARILYN HARTMAN \\ University of North Carolina, Chapel Hill, North Carolina
}

\begin{abstract}
Attentional state during acquisition is an important determinant of performance on direct memory tests. In two experiments we investigated the effects of dividing attention during acquisition on conceptually driven and data-driven indirect memory tests. Subjects read a list of words with or without distraction. Memory for the words was later tested with an indirect memory test or a direct memory test that differed only in task instructions. In Experiment 1, the indirect test was categoryexemplar production (a conceptually driven task) and the direct test was category-cued recall. In Experiment 2, the indirect test was word-fragment completion (a data-driven task) and the direct test was word-fragment cued recall. Dividing attention at encoding decreased performance on both direct memory tests. Of the indirect tests, category-exemplar production but not word-fragment completion was affected. The results indicate that conceptually driven indirect memory tests, like direct memory tests, are affected by divided attention, whereas data-driven indirect tests are not. These results are interpreted within the transfer-appropriate processing framework.
\end{abstract}

Traditional memory tests typically require that the subject think back about some prior (usually experimenterprovided) experiences and try to retrieve information about those events. Such tests are called direct or explicit memory tests (e.g., recognition and free or cued recall) and may be contrasted with tests of unintentional or incidental memory retrieval, known as indirect or implicit memory tests. On indirect tests, the subject is simply asked to perform a task, such as the identification of perceptually degraded stimuli or the completion of word fragments, with no mention made of the relationship between the test and any earlier experiences. Memory for prior events is inferred from the increased ease in identifying, generating, or otherwise processing previously experienced information. The enhanced performance on indirect memory tasks is called priming. ${ }^{1}$ As typically conceived, direct tests measure primarily intentional or deliberate recollection, whereas indirect tests measure primarily unintentional or unconscious influences of memory (Richardson-Klavehn \& Bjork, 1988; Schacter, 1992; Squire, 1992).

The principles that govern performance on direct and indirect memory tests appear to differ in many ways (see Richardson-Klavehn \& Bjork, 1988; Roediger \& McDermott, 1993; Schacter, 1987, for reviews). For instance, variation in the amount of semantic processing at encoding (e.g., the levels-of-processing manipulation) has marked

This research was supported in part by National Institute on Aging Grant AG10593-01 to M.H. A portion of these results was presented at the annual meeting of the American Psychological Society, Washington, DC, in July 1994. We thank George Wolford, Kathleen McDermott, and an anonymous reviewer for helpful comments on an earlier version of this article. We wish to acknowledge Valerie Chen for her assistance in data collection. Correspondence should be addressed to N. W. Mulligan, whose current address is Illinois State University, Department of Psychology, Campus Box 4620, Normal, IL 617904620 (e-mail: nwmulli@rs6000.cmp.ilstu.edu). effects on many direct memory tests but little effect on many indirect memory tests (Graf \& Mandler, 1984; Jacoby \& Dallas, 1981; but see Challis \& Brodbeck, 1992, for an exception). Conversely, the similarity between the physical features of the stimuli as presented at the time of study and test has a strong impact on many indirect memory tests but little or none on direct tests (Craik, Moscovitch, \& McDowd, 1994; Rajaram \& Roediger, 1993; Roediger \& Blaxton, 1987; but see Mulligan \& Hirshman, 1995 , for an exception). Such functional dissociations of direct and indirect memory tests, as well as the theoretical explanation of these dissociations, have been central to much of current memory research (Roediger \& $\mathrm{Mc}$ Dermott, 1993).

One prominent account of the pattern of functional dissociations is the transfer-appropriate processing (TAP) framework (Blaxton, 1989; Roediger, 1990; Roediger, Weldon, \& Challis, 1989). In the TAP framework, it is assumed that performance on a memory test benefits to the extent that cognitive processes carried out during encoding are reengaged at test (Morris, Bransford, \& Franks, 1977). Furthermore, the TAP framework distinguishes between two broad classes of memory processing, conceptually driven processing and data-driven processing (Blaxton, 1989; Jacoby, 1983; Roediger, 1990; Roediger et al., 1989). Conceptually driven processing involves the analysis of meaning, whereas data-driven processing involves the analysis of perceptual or surface-level features.

In the TAP view, it is asserted that direct and indirect memory tests often rely differentially on conceptually driven and data-driven processing, and consequently benefit from different types of encoding procedures. The most widely used indirect memory tests involve degraded or ambiguous perceptual cues, such as word fragments or stems, briefly presented words, or fragmented pictures. In the TAP view, it is emphasized that such tests rely heavily on data-driven processing and thus are sensitive to the 
similarity between perceptual processes engaged at study and test. In contrast, direct memory instructions generally encourage the reengagement of conceptual or elaborative memory processes (Craik et al., 1994; Roediger et al., 1989).

In the TAP approach it is explicitly stated, however, that the distinction between data-driven and conceptually driven processing is not coextensive with the distinction between indirect and direct test instructions. According to TAP, functional dissociations of direct and indirect tests are only indirectly attributable to test instructions; it is the types of memory cues in conjunction with the test instructions, rather than the test instructions per se, that determine whether a test primarily engages data-driven or conceptually driven processing. Accordingly, one can develop conceptually driven indirect memory tests as well as data-driven direct memory tests (Blaxton, 1989, 1992; Srinivas \& Roediger, 1990). In the TAP framework it is predicted that functional dissociations are likely to occur between two direct tests, or between two indirect tests, if one is data driven and the other is conceptually driven. When test instructions (direct vs. indirect) and type of test cue (perceptual vs. conceptual) are factorally manipulated, such dissociations have indeed been uncovered (e.g., Blaxton, 1989; Srinivas \& Roediger, 1990).

In the present study, we adopt the perspective of the TAP framework to investigate the role of attention in direct and indirect memory tests. The role of attention in these two types of tests has not been studied systematically, and it is important to do so for two reasons. First, attention may prove to be another variable that produces functional dissociations between indirect and direct memory tests, or between data-driven and conceptually driven indirect memory tests. There is currently insufficient evidence to draw any conclusions about this, as will be discussed below. Second, some researchers have recently suggested that performance on indirect memory tests reflects automatic encoding processes, whereas performance on direct memory tests reflects encoding processes that require attentional resources (Besson, Fischler, Boaz, \& Raney, 1992; Graf \& Mandler, 1984; Jacoby, Toth, \& Yonelinas, 1993; Jacoby, Woloshyn, \& Kelley, 1989; Jelicic, Bonke, Wolters, \& Phaf, 1992; Parkin, Reid, \& Russo, 1990; Parkin \& Russo, 1990). ${ }^{2}$ In the latter view, which we call the attentional view, it is predicted that manipulations of attention will affect direct memory tests but not indirect memory tests. Before evaluating the extent to which the TAP view and the attentional view coincide, we will briefly discuss current evidence regarding the role of attention in direct and indirect memory tests.

It has long been known that attentional state during acquisition is an important determinant of performance on direct memory tests, such as recognition (Fisk \& Schneider, 1984; Moray, 1959; Norman, 1969) and free and cued recall (Baddeley, Lewis, Eldridge, \& Thompson, 1984; Murdock, 1965). When attention is diverted from an in- formation source by a very distracting task, such as the dichotic listening task, direct memory tests may provide no evidence of retention (Cherry, 1953; Moray, 1959). Nevertheless, indirect memory tests may demonstrate some learning (Eich, 1984; Jelicic et al., 1992; KunstWilson \& Zajonc, 1980; MacKay, 1973; Mandler, Nakamura, \& Van Zandt, 1987; Merickle \& Reingold, 1991; Seamon, Marsh, \& Brody, 1984). For instance, Eich (1984) used a dichotic listening task in which the unattended channel included a series of homophones together with words that biased their less frequent meaning (e.g., taxi-FARE). Subjects showed no memory for the unattended homophones when memory was tested with a direct test of recognition. However, when the subjects were simply asked to spell the target homophones, with no overt reference to the listening task, there was a greater likelihood of choosing the biased rather than the unbiased spelling. Thus, an indirect test of memory indicated that information about the unattended information was retained.

More generally, several researchers have found that indirect tests are more likely to show retention of poorly attended stimuli than are direct tests (e.g., Bornstein, Leone, \& Galley, 1987; Hawley \& Johnston, 1991; KunstWilson \& Zajonc, 1980; Mandler et al., 1987; Merickle $\&$ Reingold, 1991). In addition, under some conditions the amount of priming is equivalent for full and dividedattention encoding conditions (Jacoby et al., 1989; Parkin et al., 1990; Parkin \& Russo, 1990; Russo \& Parkin, 1993; Smith \& Oscar-Berman, 1990). This equivalence has been demonstrated for the word-fragment completion test (Parkin et al., 1990), the picture-fragment completion test (Parkin \& Russo, 1990; Russo \& Parkin, 1993), lexical decision (Smith \& Oscar-Berman, 1990), and the famejudgment task developed by Jacoby and his colleagues (Jacoby et al., 1989). In these same studies, dividing attention reduced performance on direct tests, such as recognition memory (Parkin et al., 1990) and recall tests (Parkin \& Russo, 1990; Russo \& Parkin, 1993).

These results are compelling and suggest that the memory processes measured by direct and indirect memory tests have different attentional requirements (Parkin \& Russo, 1990; Jacoby et al., 1993). But how general is this view? The TAP framework suggests an important limitation for this interpretation of the evidence. If it is assumed that dividing attention at study reduces the amount of elaboration or semantic processing (see, e.g., Craik, 1983; Craik \& Byrd, 1982) but has little or no effect on perceptual identification processes, then the TAP framework makes two predictions: (1) Divided attention should have little or no effect on data-driven tests; and (2) divided attention should reduce priming on conceptually driven tests. Consequently, the TAP view predicts that divided attention will produce a functional dissociation when a data-driven indirect test is compared with a conceptually driven direct test. If conceptually driven indirect and direct tests are compared, the TAP view predicts no dissociation. 
With regard to the distinction between data-driven and conceptually driven tests, it should be noted that most of the prior research on the role of attention in priming has focused on data-driven indirect memory tests, such as word- and picture-fragment completion (Parkin et al., 1990; Parkin \& Russo, 1990; Russo \& Parkin, 1993) and lexical decision (Smith \& Oscar-Berman, 1990). Much of this data is consistent with the TAP prediction, indicating little or no effect of divided attention on priming in data-driven indirect tests (we will address some exceptions, e.g., Hawley \& Johnston, 1991, in later discussion). Other studies examining the effects of dividing attention have utilized tests, such as the fame-judgment task (Jacoby et al., 1989) and homophone spelling (Eich, 1984), that are not clearly either data driven or conceptually driven. According to the TAP framework, a memory test is classified as primarily data driven or conceptually driven on the basis of how the test responds to certain criterial variables, such as the generation manipulation, perceptual manipulations, and organizational manipulations (Roediger et al., 1989; Srinivas \& Roediger, 1990). Neither the fame-judgment task nor the homophone-spelling task has been classified with these criterial variables.

Only one study has employed an indirect test that is presumably conceptually driven, the word-association task. Koriat and Feuerstein (1976) found that divided attention had no effect on priming in a word-association test, but produced large effects on free recall and recognition, rendering a functional dissociation of indirect (word-association) and direct (free-recall and recognition) tests. However, it should be noted that in the Koriat and Feuerstein study (1976), the direct and indirect tests differed in several ways besides task instructions. Both the type of memory cues and the response requirements differed across the word-association, free-recall and recognition tests. Therefore, it is not possible to uniquely attribute the differential effects of divided attention to the type of test (i.e., direct vs. indirect). Consequently, it is still an open question whether divided attention will produce a dissociation between a conceptually driven indirect test and a comparable direct test. The attentional view suggests that such a dissociation will occur; the TAP view predicts that it will not.

When it comes to data-driven indirect tests, it is also unknown whether dividing attention produces a dissociation between data-driven indirect memory tests and comparable direct tests. Although several of the studies mentioned above found dissociations between indirect and direct memory tests, there were typically several differences between the memory tests besides test instructions (Parkin et al., 1990; Parkin \& Russo, 1990; Russo \& Parkin, 1993; Smith \& Oscar-Berman, 1990). In order to determine whether the differentiating effects of divided attention are due to the direct/indirect difference, one needs to compare performance on two memory tests that are identical in all regards except test instructions (Neely, 1989; Schacter, Bowers, \& Booker, 1989). The TAP view predicts equivalent levels of priming on a data-driven test, provided that a sufficient amount of bottom-up perceptual processing occurs in both the full and divided attention conditions. In contrast, because conceptually driven processes play a larger role in direct memory tests (see, e.g., Craik et al., 1994; Graf \& Mandler, 1984; Roediger, Weldon, Stadler, \& Riegler, 1992), the TAP view suggests that changing the instructions of a data-driven indirect test to make it a direct test would produce a memory test that is sensitive to the effects of divided attention. Consequently, the TAP view suggests that divided attention would dissociate the direct and indirect versions of an otherwise identical data-driven memory test.

The goal of the present study was to systematically examine the role of attention on indirect memory tests. The first experiment utilized the category-exemplar production test, an indirect test classified as conceptually driven because it benefited from semantic and organizational processes at encoding (Hamman, 1990; Rappold \& Hashtroudi, 1991; Srinivas \& Roediger, 1990). The second experiment utilized the word-fragment completion test, a widely used indirect test classified as data driven according to the criteria of the TAP framework (Blaxton, 1989; Srinivas \& Roediger, 1990). Each experiment included a completely parallel direct memory test that differred from the indirect test only in instructions. The direct tests were category-cued recall and word-fragment cued recall for the first and second experiments, respectively. In addition, the two experiments used the same study materials and the same divided attention task in order to facilitate comparison across experiments. This arrangement permitted a strong test of the role of attention on different types of memory tests.

\section{EXPERIMENT 1}

In Experiment 1, we examined the effects of divided attention on the conceptually driven test of categoryexemplar production and two variants of category-cued recall. During the study portion of this experiment, subjects were presented with a randomized list of 48 words, consisting of six exemplars from each of eight taxonomic categories. The study list was presented under either full or divided attention conditions. On the memory test, subjects were presented with a set of category names to use as memory cues. In the category-exemplar production task, the subjects were presented with 16 category cues ( 8 studied categories and 8 new categories) and asked to produce 8 exemplars from each category. No mention was made of the relationship between the study list and the category-exemplar production task. Performance on this task was compared to performance on a modified category-cued recall task, a direct memory test designed to be identical to category-exemplar production in all but task instructions (Neely, 1989; Schacter et al., 1989). In the modified category-cued recall test, all 16 categories were presented. Subjects were asked to use each category cue to try to remember words from the study list but, when no more study words could be re- 
called, to continue producing category exemplars until a total of eight exemplars from the category was produced. Note that the modified category-cued recall utilized the identical cues and required the same number of responses per category as did the category-exemplar production task. It differed only in the instructions to subjects. In addition to the modified category-cued recall test, a standard category-cued recall was used. In this test, only the eight studied categories were presented and subjects were asked to use each category cue to recall words from the study list. This task was used to check the generality of the results from the modified categorycued recall.

\section{Method}

Subjects. The subjects were 84 undergraduates at the University of North Carolina at Chapel Hill. Subjects participated as part of an introductory class requirement.

Design and Materials. We used a $2 \times 2 \times 3$ design in which study status (studied vs. new, or nonstudied) was manipulated within-subject and attention at encoding (full vs. divided) and memory test type (category-exemplar production, modified categorycued recall [modified-CCR], and category-cued recall) was manipulated between-subjects.

The selection of the materials followed Graf, Shimamura, and Squire (1985) and Rappold and Hashtroudi (1991). Six common instances, from 5 to 10 letters in length, were chosen from each of 16 categories (a sport, a fruit, a piece of furniture, a bird, a color, a four-footed animal, an article of clothing, a tree, a musical instrument, a part of the human body, a vegetable, a dance, an insect, a substance for flavoring food, a fish, a part of a building) in the Battig and Montague (1969) norms. The items chosen did not rank in the 10 most frequent instances, but were produced by at least 10 of the 400 subjects used in the Battig and Montague norms. The average rank of the selected category members was 17.4.

Two study lists were created by randomly assigning eight of the categories to one study list and the other eight to the second list. This yielded two lists with 48 critical items each. The critical items in each list were randomly ordered, subject to the constraint that no two consecutive items were from the same category. Eight additional items were chosen from nonselected Battig and Montague (1969) categories to serve as buffers in the study lists. Half of these items were placed at the beginning of each list and served as a primacy buffer, while the other half were placed at the end of each list and served as a recency buffer. Each item came from a different category, and the average rank of these items was similar to that of the critical items (14.5; Battig \& Montague, 1969). Each of the two study lists was presented to one half of the subjects.

In the category-exemplar production test and modified-CCR test, all 16 category names were used as cues. Eight of the categories corresponded to studied words, and eight to new words. Production rates of the nonstudied critical items served as the baseline response rate in these two tasks. Across subjects, each category appeared equally often as studied and new. In the categorycued recall task, the cue set consisted of the eight category names corresponding to the studied items.

The task used in the divided-attention condition was a digitmonitoring task (Craik, 1982; Jacoby, 1991). Subjects monitored a tape-recorded series of random digits, attempting to detect target sequences of three odd digits in a row. The digits were played at the rate of one digit per $1.5 \mathrm{sec}$. There were 32 target sequences randomly distributed through the series of 180 digits, subject to two constraints: (1) a minimum of one and a maximum of five numbers occurred between the end of one target sequence and the beginning of the next; and (2) not more that two even digits occurred in sequence. The list of 180 digits was recorded six times from beginning to end without pause between repetitions.

Procedure. Subjects were tested individually. The experiment consisted of three parts: a study task, a distractor task, and a memory test. At the beginning of the experiment, subjects were informed that they would perform several different tasks, some having to do with memory and some having to do with language abilities and problem solving.

During the study task, each study item was displayed in the center of a computer screen for $3 \mathrm{sec}$. Subjects were instructed to read each word out loud and to try to remember the words for a later memory test. Subjects in the divided-attention condition simultaneously performed the digit-monitoring task. These subjects were told to monitor the digits for strings of three odd numbers in a row and to tap a pen on the desk whenever they detected a target string. If a subject missed a target sequence, the experimenter prompted the subject by saying "miss." The experimenter monitored and recorded errors in reading the words and detecting target sequences of digits.

Following the presentation of the words, subjects completed a 3-min distractor task. This was used to disguise the relationship between the study session and the subsequent memory test by making the memory test seem to be one in a series of unrelated tasks. The distractor task used was a stem-completion task with city names. Subjects were presented with a series of index cards, on each of which were the first three letters of a U.S. city (e.g., Bos _ for Boston). They were asked to complete each city word stem with the name of a U.S. city.

After the distractor task, subjects were given one of the three memory tests. In the category-exemplar production task, the 16 category names were displayed, one at a time, on a computer screen. Subjects were instructed to say aloud as rapidly as possible the first eight category exemplars that came to mind. Eight exemplars were required to be sure that exemplars other than the most common were produced (Graf et al., 1985; Rappold \& Hashtroudi, 1991). An experimenter recorded the subjects' responses and no time limit was imposed. When eight exemplars were produced, the experimenter signaled the subject to proceed to the next category by pressing the space bar on the computer keyboard. No mention was made of the relationship between this task and the studied words. After subjects completed the category-exemplar production task, they were asked a series of questions (the awareness questionnaire) to assess whether they had noticed the relationship between the study task and the memory test, and the extent to which they had deliberately tried to retrieve study items.

The modified category-cued recall was identical to the categoryexemplar production task in all but instructions. As in the categoryexemplar production task, subjects were presented with the 16 category names ( 8 studied and 8 new) one at a time. They were told that this was a memory test and they were given the following instructions:

Some of these categories correspond to words from the list that you read earlier, and some do not. For each category, say eight things that belong to the category, trying to use as many words from the list as you can remember. That means you should first try to remember words from the list that are members of the category. When you can no longer remember any, start saying other category members that come to mind, until you have reached a total of eight.

As in the indirect memory test, the experimenter kept count of the number of different exemplars produced and, when the count reached eight, signaled the subject to proceed to the next category.

In the category-cued recall test, subjects were presented with the eight category names that corresponded to the study list. The category names were displayed, one at a time, on a computer screen. The subjects were instructed to use the category cues to recall members of the category that had been studied previously. No 
time limit was imposed, and the number of responses required was not fixed.

\section{Results and Discussion}

During the study task, subjects in the divided-attention condition correctly identified $99 \%$ of the study words and detected $85 \%$ of the target digit strings. Thus, subjects in the divided attention condition were able to identify virtually all study words while simultaneously identifying most of the target sequences. However, because identification of study items occurred at a slightly higher rate in the full-attention condition $(100 \%)$, the data from the memory tests were analyzed in two ways, conditionalized on correct identification at study and unconditionalized. Both analyses led to the same conclusions. Only the results of the unconditionalized data are reported below. Table 1 summarizes the results of the memory tests. Proportions of items produced are presented as a function of test type, attention at encoding, and study status.

The data from the category-exemplar production task were submitted to a $2 \times 2$ analysis of variance (ANOVA) with study status (studied vs. new) as a within-subject factor and attention at encoding (full vs. divided) as a betweensubjects factor. The analysis revealed three significant effects: (1) a main effect of study status $[F(1,26)=35.86$, $\left.M S_{\mathrm{e}}=0.0462, p<.0001\right] ;(2)$ a main effect of attention $\left[F(1,26)=11.32, M S_{\mathrm{e}}=0.0682, p<.003\right]$; and (3) an interaction between study status and attention $[F(1,26)=$ $\left.16.71, M S_{\mathrm{e}}=0.0462, p<.0004\right]$. These results indicate significant overall priming in that more studied words than new words were produced; however, dividing attention decreased the amount of priming. Further analyses revealed a significant effect of attention for the studied items $[t(26)=5.24, p<.0001]$, but not for the new items $(p>$ .5). Additional $t$ tests indicated a significant effect of study status (i.e., priming) in the full-attention condition $[t(13)=$ $7.65, p<.0001]$, but not in the divided-attention condition $(p>.20)$. Thus, no priming was obtained in the divided-attention condition.

The data from the modified-CCR test were also submitted to a $2 \times 2$ ANOVA, with study status (studied vs. new) as a within-subject factor and attention at encoding (full vs. divided) as a between-subjects factor. Results were

Table 1

Experiment 1: Proportions of Responses in Category-Exemplar Production, Modified Category-Cued Recall, and Category-Cued Recall as a Function of Study Status and Attention at Encoding

\begin{tabular}{lccc}
\hline & \multicolumn{3}{c}{ Study Status } \\
\cline { 3 - 4 } Memory Test & Studied & New & Studied-New \\
\hline Category-exemplar production: & & & \\
$\quad$ Full attention & .257 & .144 & .113 \\
$\quad$ Divided attention & .165 & .144 & .021 \\
Modified category-cued recall: & & & \\
$\quad$ Full attention & .391 & .136 & .255 \\
$\quad$ Divided attention & .229 & .146 & .083 \\
Category-cued recall: & & & \\
$\quad$ Full attention & .230 & & \\
$\quad$ Divided attention & .112 & & \\
\hline
\end{tabular}

similar to those found for the category-exemplar production task: (1) a main effect of study status $[F(1,26)=$ $\left.99.18, M S_{\mathrm{e}}=0.0040, p<.0001\right]$; (2) a main effect of attention $\left[F(1,26)=20.69, M S_{\mathrm{e}}=0.0039, p<.0001\right]$; and (3) an interaction between study status and attention $\left[F(1,26)=26.07, M S_{\mathrm{e}}=0.0040, p<.0001\right]$. These results indicate that studied items were produced more frequently than were nonstudied items (evidence of abovebaseline memory performance), but that dividing attention decreased the difference between studied and new items. In other words, divided attention also affected the direct version of the category-exemplar production task. Follow-up $t$ tests indicated a significant effect of attention for the studied items $[t(22)=5.97, p<.0001]$, but not for the new items $(p>.5)$. Additional $t$ tests indicated an effect of study status in both the full-attention condition $[t(13)=8.93, p<.0001]$ and in the dividedattention condition $[t(13)=4.52, p<.0006]$. Thus, in contrast to the findings for the indirect version of this test, there is evidence of retention in both the full and dividedattention conditions in the modified-CCR task.

The results obtained with the modified-CCR were replicated with the standard category-cued recall test. These data were analyzed with a one-way ANOVA, with attention at encoding (full vs. divided) as a betweensubjects factor. Dividing attention at encoding decreased the number of studied items recalled $[F(1,26)=17.91$, $\left.M S_{\mathrm{e}}=0.0061, p<.001\right]$. A secondary measure of accuracy in standard category-cued recall is the number of intrusions produced. The mean number of intrusions did not significantly differ across the full and divided-attention conditions (2.07 and 3.07, respectively; $p>.20$ ). It should be noted that the intrusions tended to be higher frequency exemplars of the category than were the target items.

Performance levels in the full-attention condition in both the standard category-cued recall test and the categoryexemplar production task were comparable to those reported in Rappold and Hashtroudi (1991) under similar conditions, except that Rappold and Hashtroudi reported somewhat higher levels of cued recall. This may have been due to differences in either the study list length (36 in Rappold \& Hashtroudi; 48 in the present experiment) or in the retention interval (immediate test in Rappold \& Hashtroudi; 3-min distractor task in the present experiment). Either of these differences might lead to performance decrements in cued recall but not category-exemplar production (especially changes in retention interval, see Rappold \& Hashtroudi, Experiment 4).

The results of the current study indicate that divided attention has the same effect on a direct and an indirect version of the category-exemplar production task. Dividing attention at encoding decreases production of studied items on both tests. Furthermore, divided attention eliminated priming in the category-exemplar production task.

When a variable has similar effects on an indirect and a direct test, there is always the concern that the indirect test may have been contaminated with intentional retrieval strategies (i.e., that subjects treated the test as a 
direct memory test). In the present experiment, it may be that the advantage for the full-attention condition in the category-exemplar production task was due to this group's superior ability to use intentional retrieval. We evaluate this account in two ways.

First, we performed a re-analysis of the categoryexemplar production data on the basis of the results from the awareness questionnaire. To summarize, subjects were asked whether they noticed that they were producing exemplars that appeared on the study list and whether they were intentionally trying to produce words from the study list. Of the 14 subjects in the full-attention condition, 7 indicated that they were both aware of producing studied words and intentionally trying to retrieve them, 6 indicated that they were aware of producing studied words but were not intentionally trying to retrieve them, and 1 indicated no awareness that produced exemplars were from the studied list. For the divided-attention condition, the corresponding frequencies were 2,4 , and 8 . The difference in proportions across the full- and dividedattention conditions was significant $\left[\chi^{2}(2)=8.62, p<\right.$ $.05]$. Because there are differences in the number of subjects reporting intentional retrieval strategies across the full- and divided-attention conditions, it is important to re-analyze the data from the category-exemplar production task, excluding those subjects who claimed an intentional retrieval strategy. The remaining 7 subjects in the full-attention condition produced an average of $27 \%$ of the old items and $15 \%$ of the new items on the categoryexemplar task, whereas the remaining 12 subjects in the divided-attention condition produced an average of $16 \%$ of the old items and $15 \%$ of the new items. The amount of priming was significantly greater in the full-attention than in the divided-attention condition $[12 \%$ vs. $1 \%$, respectively; $\left.F(1,17)=15.52, M S_{\mathrm{e}}=0.0289, p<.001\right]$. An effect of study status (i.e., priming) was found in the full-attention condition $[t(6)=4.73, p<.003]$, but not in the divided-attention condition $(p>.5)$. This re-analysis is inconsistent with the notion that greater intentional retrieval in the full-attention condition mediates the current results.

However, it should be pointed out that of the subjects in the re-analysis, the proportions who claimed to be aware of producing at least some exemplars from the study list differed across the full- and divided-attention conditions ( 6 out of 7, and 4 out of 12, respectively; Fisher's Exact Test: $p<.05$, one-tailed). This is of concern because it is possible that subjects may not be accurate in reporting retrieval strategies and that some of those who reported awareness but not intentional retrieval may have actually engaged in some amount of unreported intentional retrieval. If so, the differences in awareness across the two attention conditions might be a by-product of differential intentional retrieval. On the other hand, subjects may become aware of the study-test relationship without engaging in intentional retrieval, a phenomenon called "involuntary conscious memory" (RichardsonKlavehn, Gardiner, \& Java, 1994). We might well expect this to occur more frequently in the full-attention condition, even in the absence of intentional retrieval strategies. ${ }^{3}$

A second way to evaluate the intentional retrieval account is to place the current results in the context of other studies. First, it is known that memory-impaired subjects have displayed normal levels of priming on category-exemplar production under conditions very similar to those in our full-attention condition (Blaxton, 1992; Graf et al., 1985). The amount of priming in the full-attention condition $(11.3 \%)$ is similar to levels that have been found with these memory-impaired subjects: $12.3 \%$ for amnesic patients of mixed etiologies in a study by Graf et al. (1985, Experiment 2) and approximately $17 \%$ for memory-impaired temporal lobe epileptics in a study by Blaxton (1992, Experiment 3, random condition). If the effects of attention in our study were mediated by the effective use of intentional retrieval by subjects in the full-attention condition, these subjects would likely produce higher levels of performance than memory-impaired subjects (see, e.g., Blaxton, 1992). Second, the amount of priming in the full-attention condition is consistent with levels found in comparable conditions in studies that satisfied the retrieval-intentionality criterion (Rappold \& Hashtroudi, 1991, Experiments $2-4$, random conditions). It seems that the effect of divided attention on category-exemplar production is not mediated by intentional retrieval in the full-attention condition but, more likely, by reduced performance in the divided-attention condition, where there is no evidence of priming.

In summary, the results of Experiment 1 indicate that the amount of attention at encoding does not produce a dissociation between the indirect memory test of categoryexemplar production and its direct counterpart, the modified category-cued recall test. This finding is consistent with the TAP view that performance on conceptually driven tests is enhanced to the extent that study processing accentuates conceptual or elaborative processing. If dividing attention at study limits the amount of conceptual or semantic processing, then according to the TAP view, there would be less transfer to conceptually driven tests. This prediction seems to have been supported.

These results also suggest an important limitation of the attentional view discussed earlier. This view suggests that indirect tests of memory are more sensitive to automatic, non-attention-demanding encoding processes than are direct tests of memory. The expectation under this view is that direct tests should be more sensitive to manipulations of attention than are indirect tests. But as we have seen, dividing attention had comparable effects on category-exemplar production and category-cued recall. Furthermore, dividing attention eliminated retention as measured by the indirect test but not as measured by the direct test.

On the surface, the current results seem to conflict with the results of Koriat and Feuerstein (1976). These authors found that divided attention had no effect on the conceptually driven indirect test of word association, 
whereas it had a large effect on the direct tests of recognition and recall. This contrasts with the results of the present study, in which strong effects of divided attention were found on both a conceptually driven indirect task and a comparable direct test. Koriat and Feuerstein's results suggest that effects of divided attention may not always be observed on conceptually driven indirect tests. There are several differences between the Koriat and Feuerstein study and the present study, any of which may account for these divergent results. First, different tasks to divide attention were used in the two studies. It may be that the digit-monitoring task used in our experiment more effectively divides attention than does the digit-symbol task used by Koriat and Feuerstein. Second, Koriat and Feuerstein used strongly associated items (e.g., doctornurse) for their word-association task, whereas we used category exemplars that were not as strongly associated with the category cues (recall that the exemplars used in the present study did not rank in the 10 most frequently produced instances, according to the Battig and Montague, 1969, norms). It is possible that the use of very strong associates eliminates the need for elaborative processing to produce relatively accessible memory traces. A final consideration is that Koriat and Feuerstein did not use parallel direct and indirect tests. It may be that a direct memory test version of Koriat and Feuerstein's wordassociation task would not have been affected by divided attention, given their materials and attentional manipulation. At present, we cannot say which of the differences accounts for the discrepant results. We can say, however, that dividing attention has profound effects on the conceptually driven test of category-exemplar production.

\section{EXPERIMENT 2}

The results of Experiment 1 are consistent with the predictions of the TAP framework: Divided attention did not produce a dissociation between direct and indirect versions of a conceptually driven memory test. Under this framework the complementary prediction is that divided attention will produce a dissociation when a datadriven indirect test is compared to a direct version of the same task. To test this hypothesis, we examined the effects of divided attention on the word-fragment completion test and its direct test counterpart, word-fragment cued recall. The word-fragment cued recall test consisted of the identical test cues and types of responses as word-fragment completion, differing only in the instructions to the subject. On the TAP view, word-fragment completion would be unaffected by divided attention, whereas performance on the word-fragment cued recall test would be reduced. As mentioned earlier, Parkin et al. (1990) found that divided attention had no effect on wordfragment completion, but did produce a marked decrease in recognition memory performance. These findings are consistent with the TAP view; however, the indirect and direct tests used were not completely comparable. As such, we cannot uniquely attribute this dissociation to the task instructions. The obtained pattern of results may have been due to some other difference between wordfragment completion and recognition memory tests, such as the types of cues used or the response demands. Thus, the current experiment was designed to be a stronger test of the effects of attention.

\section{Method}

Subjects. The subjects were 56 undergraduates at the University of North Carolina at Chapel Hill, who participated as part of an introductory class requirement.

Design and Materials. We used a $2 \times 2 \times 2$ design in which study status (studied vs. new) was manipulated within-subject and attention at encoding (full vs. divided) and memory test type (word-fragment completion vs. word-fragment cued recall) were manipulated between-subjects.

To render this experiment as comparable as possible to Experiment 1 , the same study lists, divided attention task and distractor task were used. The memory tests consisted of a total of 104 word fragments, of which 96 corresponded to the critical items from the two study lists. Forty-eight of the fragments corresponded to studied items, and 48 were new items. An additional eight words were chosen from eight previously unused categories of the Battig and Montague (1969) norms. Four of the additional word fragments were placed at the beginning of the test, and the rest of the word fragments (studied, new, and additional) were randomly distributed throughout the list with the constraint that there be no more than two items in a row of any single type. This yielded a test list in which slightly less than half of the fragments corresponded to studied words. The studied and new items were counterbalanced so that, across subjects, each word appeared equally often as studied and new.

The fragments consisted of between two and six letters, with underscores in the place of missing letters (e.g., $e l_{-} p_{\ldots} n t$ for elephant). Using the spell check facility of the WordPerfect program (Version 5.1), we constructed fragments that, according to the electronic dictionary accompanying WordPerfect, were consistent with only one English word completion. Pilot testing was performed to select a set of fragments of appropriate difficulty ( $25 \%$ $30 \%$ completion for new items). Forty subjects from the same pool as the experimental subjects completed candidate word fragments. The mean completion rate for the chosen fragments was $28 \%$. The pilot subjects and the subsequent experimental subjects never completed a fragment with any word other than the intended one.

Procedure. Subjects were tested individually. The experiment consisted of three parts: the study task, the distractor task, and a memory test. The study and distractor tasks were identical to those in Experiment 1.

After the distractor task, subjects were given one of the two memory tests. For both tests, subjects were given a sheet of paper with the 104 fragments that were numbered and arranged in three columns. In the word-fragment completion task, subjects were asked to try to complete each word fragment with an appropriate word. No mention was made of the relationship between this task and the study task. In the word-fragment cued recall test, the subjects were told that their memory was being tested. They were also informed that some of the fragments corresponded to words from the study list and some did not. The subjects were asked to try to recall words from the study list that completed the fragments, and told that if they could not do so to complete the fragment with any appropriate word that came to mind. These guessing instructions were used in an attempt to equate response bias across the direct and indirect tests. Response requirements (and the biases they induce) typically differ across the two types of memory tests. The present instructions were designed to make the two tests more comparable. 
For both memory tests, the subjects were given $12 \mathrm{sec}$ for each fragment. Time was kept with an audiotape that emitted a beep every $12 \mathrm{sec}$. Subjects were instructed to use the entire $12 \mathrm{sec}$ on the current fragment, not to work backward, and to move on to the next fragment only after hearing the beep. The subjects were given a cover sheet to keep their place.

\section{Results and Discussion}

During the study task, subjects in the divided-attention condition correctly identified $99.5 \%$ of the study words and detected $87 \%$ of the target digit strings. Thus, as in Experiment 1, subjects in the divided-attention condition were able to identify virtually all study words while simultaneously identifying most of the target sequences. However, because identification of study items occurred at a slightly higher rate in the full-attention condition $(100 \%)$, the data from the memory tests were analyzed in two ways, conditionalized on correct identification at study and unconditionalized. Given the high rate of correct identification at study, it is not surprising that both analyses led to the same conclusions. Only the results of the unconditionalized data are reported below. Table 2 summarizes the results of the memory tests. Proportions of fragments completed are presented as a function of test type, attention at encoding, and study status.

The data from the word-fragment completion and word-fragment cued recall were submitted to separate $2 \times 2$ ANOVAs, with study status (studied vs. new) as a within-subject factor and attention at encoding (full vs. divided) as a between-subjects factor. For the wordfragment completion test, the analysis revealed a main effect of study status $\left[F(1,26)=42.33, M S_{\mathrm{e}}=0.0104\right.$, $p<.0001]$, indicating that presentation at study led to higher rates of fragment completion (i.e., significant priming occurred). No effects involving attention were significant $(F \mathrm{~s}<1)$. The corresponding ANOVA for word-fragment cued recall produced two significant results: a main effect of study status $[F(1,26)=61.43$, $\left.M S_{\mathrm{e}}=0.0135, p<.0001\right]$, indicating above-baseline recall of the studied items; and a study status $\times$ attention interaction $\left[F(1,26)=5.07, M S_{\mathrm{e}}=0.0135, p<.03\right]$ indicating that the studied-new difference was greater in the full-attention condition. Thus, divided attention affected the word-fragment cued recall test. Follow-up $t$ tests indicated that the attention manipulation affected the studied items $[t(26)=1.84, p<.04$, one-tailed], but

Table 2

Experiment 2: Proportions of Correct Responses in Word-Fragment Completion and Word-Fragment Cued Recall as a Function of Study Status and Attention at Encoding

\begin{tabular}{lllc}
\hline & \multicolumn{3}{c}{ Study Status } \\
\cline { 2 - 4 } Memory Test & Studied & New & Studied-New \\
\hline Word-fragment completion: & & & \\
$\quad$ Full attention & .466 & .283 & .183 \\
$\quad$ Divided attention & .431 & .260 & .171 \\
Word-fragment cued recall: & & & \\
$\quad$ Full attention & .545 & .231 & .314 \\
$\quad$ Divided attention & .440 & .266 & .174 \\
\hline
\end{tabular}

not the new items $(p>.35)$. There was also a significant effect of study status in both the full-attention condition $[t(13)=6.33, p<.0001]$ and the divided-attention condition $[t(13)=4.62, p<.0006]$.

To summarize, dividing attention had no effect on priming in the word-fragment completion test, but a significant effect on performance in the word-fragment cued recall test. These results replicate and extend the findings of Parkin et al. (1990), who also showed that priming on the word-fragment completion test is unaffected by divided attention. By demonstrating that divided attention produces a dissociation between a direct and an indirect memory test that differ only in test instructions, we have provided stronger evidence that this dissociation is due to test instructions. In addition, these results bolster claims that divided attention does not affect data-driven indirect tests.

The finding that dividing attention did not affect a data-driven indirect memory test is expected under the TAP framework, provided that this manipulation does not disrupt data-driven encoding processes. The nearperfect identification of study words indicates that this holds in the present experiment. Furthermore, consideration of this proviso may shed light on apparently conflicting results in the literature. Some studies (including the present experiment) indicate no effect of dividing attention on data-driven indirect tests (Parkin et al., 1990; Parkin \& Russo, 1990; Russo \& Parkin, 1993; Smith \& Oscar-Berman, 1990), whereas others indicate that dividing attention decreases the amount of priming on this type of memory test (Hawley \& Johnston, 1991). These conflicting results may simply be due to the use of different memory tests by different researchers, but that may not be the most parsimonious account. Memory tests that have shown null effects of divided attention include word-fragment completion (this experiment; Parkin et al., 1990), picture-fragment completion (Parkin \& Russo, 1990), lexical decision (Smith \& Oscar-Berman, 1990), and the fame-judgment task (Jacoby et al., 1989). Memory tests that have displayed sensitivity to divided attention include homophone spelling (Eich, 1984) and speeded naming of perceptually degraded words (Hawley \& Johnston, 1991). ${ }^{4}$ There is no obvious difference between the types of memory tests that have displayed sensitivity to divided attention and those that have not.

On the other hand, there do seem to be systematic differences in the divided attention manipulation across the two sets of studies. In the studies in which divided attention reduced priming, the dual-task manipulation rendered overt (or covert) identification of the study items unlikely or nearly impossible (see also Jacoby \& Brooks, 1984; Seamon, Brody, \& Kauff, 1983). In contrast, in those studies that produced no effect of divided attention, the divided-attention manipulation rendered overt (or covert) identification very likely, and in most of these studies, overt identification of the study items was required (e.g., the present experiment; Jacoby et al., 1989; Parkin et al., 1990; Russo \& Parkin, 1993; Smith \& Oscar-Berman, 1990). This suggests that dividing atten- 
tion impairs priming on data-driven indirect memory tests when the attentional manipulation disrupts identification of the study items. If the attentional manipulation does not disrupt identification, then priming is unaffected. It should be noted that this analysis is consistent with the results of studies utilizing very brief presentation durations at encoding (Gellatly, Parker, Blurton, \& Woods, 1994; Hawley \& Johnston, 1991; Seamon et al., 1984). These researchers found that priming increased with identification rates at encoding, indicating that disrupting identification has deleterious effects on priming in data-driven tasks.

Finally, we note that the TAP framework correctly predicted that word-fragment cued recall would be sensitive to the effects of divided attention. Although the memory cues are the same as in the word-fragment completion test, the TAP view suggests that the intentional retrieval processes induced by direct test instructions render the cued recall test sensitive to prior conceptually driven processing (Craik et al., 1994; Roediger et al., 1992). In fact, Roediger et al. (1992) have demonstrated that this task is affected by the levels-of-processing manipulation, one of the criterial variables labeling a test as conceptually driven according to the TAP framework. This leads to the expectation that this task would be affected by attentional manipulations that disrupt conceptual encoding.

\section{GENERAL DISCUSSION}

The results of both experiments are summarized in Figure 1. Divided attention decreased priming in the category-exemplar production test, but not in the wordfragment completion test (upper panel). In other words, divided attention produced a dissociation between these two indirect memory tests. In contrast, divided attention had similar effects on performance in the direct versions of both tests (lower panel). Thus, the findings indicate that, with regard to the effects of attention, a conceptually driven indirect memory test is more similar to direct tests of memory than to a data-driven indirect test. ${ }^{5} \mathrm{Be}-$ fore proceeding, we note that although it is possible that conceptually driven indirect tests may simply be more likely to lead to intentional retrieval than are data-driven indirect tests, we view this as an unlikely account of the present results (see discussion of Experiment 1).

These results are consistent with the TAP view. Because there is greater conceptual or semantic processing in the full-attention than in the divided-attention condition, reducing the amount of available attentional resources should affect only the indirect memory test that is highly dependent on such processing. Importantly, these results limit the generality of the view that divided attention has little effect on unintentional or unconscious manifestations of memory (Jacoby et al., 1989; Jacoby et al., 1993; Parkin \& Russo, 1990). It appears that effects of divided attention will be obtained when the indirect memory test has a strong conceptual component.
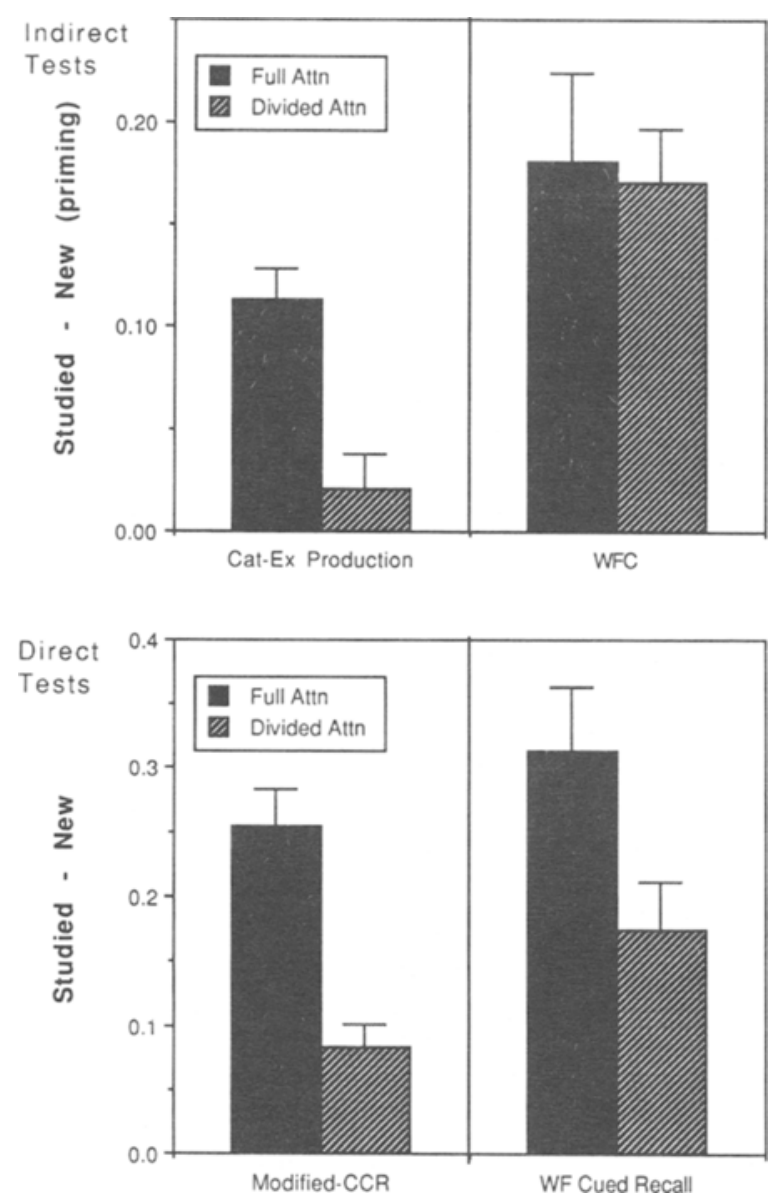

Figure 1. Summary of results of Experiments 1 and 2: mean difference (and $S E$ bars) between proportions of studied and new items produced at test as a function of attention condition and test type (Cat-Ex Production, category-exemplar production; WFC, word-fragment completion; Modified-CCR, modified categorycued recall; WF Cued Recall, word-fragment cued recall).

\section{Divided Attention and Levels-of-Processing}

According to the TAP framework, the effects of attention at encoding are expected to be similar to those of levels-of-processing because both manipulations affect the amount of semantic or conceptual processing. The full-attention condition should lead to greater semantic and conceptual processing, whereas the divided-attention condition should limit encoding operations to those necessary for stimulus identification. As such, both levelsof-processing and attention at encoding should affect conceptually driven indirect tests, but not data-driven indirect tests. The present study reveals just such a set of findings for the attention variable: Dividing attention affects category-exemplar production but not word-fragment completion. Correspondingly, levels-of-processing has robust effects on conceptually driven tests, such as categoryexemplar production (Hamman, 1990; Srinivas \& Roediger, 1990) and general knowledge questions (Hamman, 1990), but has little or no effect on many data-driven 
tests, such as word-fragment completion (see, e.g., Roediger et al., 1992) and word-stem completion (e.g., Graf \& Mandler, 1984).

However, with regard to word-fragment completion, there is one apparent difference between the effects of attention and levels-of-processing. Recently, Challis and Brodbeck (1992) have shown that when levels-ofprocessing is manipulated between subjects (or blocked within subjects), it has unexpectedly large effects on word fragment completion. If the effects of attention and levels-of-processing have a common source, one might expect that when attention is manipulated between subjects, it too will affect word-fragment completion. However, attention was manipulated between-subjects in Experiment 2 , and it produced no effect on word-fragment completion.

We may resolve this apparent discrepancy by considering one of the potential explanations offered by Challis and Brodbeck (1992) for their findings (see also Roediger \& McDermott, 1993). It may be that the levelsof-processing manipulation affects not only the amount of conceptual processing but also the amount or kind of perceptual processing. In particular, different levels of processing may differ in the degree of lexical access required. For instance, a nonsemantic encoding task that requires a search for the letter $e$ may be performed without engaging the same perceptual processes necessary for word identification (lexical access). Lexical access has been identified as an important determinant for priming on data-driven tasks (Weldon, 1991). In contrast, judgments concerning the meaning of a word, as used to induce deeper levels of processing, presumably require lexical access. As such, the nonsemantic orienting task may encourage a truncation of perceptual analysis relative to a semantic orienting task (Hayman \& Jacoby, 1989; Roediger \& McDermott, 1993). Challis and Brodbeck (1992) have argued that such a strategy may be very pronounced when the nonsemantic task is blocked or presented in a pure list (i.e., between subjects). This would lead to an advantage for the semantic condition in the data-driven priming test of word-fragment completion.

The apparent discrepancy between the effects of levelsof-processing and divided attention effects may be resolved if our attention manipulation did not lead to differential perceptual processing (e.g., lexical access) in the full- and divided-attention conditions. Indeed, the fact that the divided-attention condition produced nearperfect word identification during the study task indicates that the perceptual analysis necessary for word identification was carried out. Furthermore, it is important to note that not all attentional manipulations are equivalent. As discussed earlier, it is possible that other manipulations of attention might disrupt perceptual processing. In such cases, one would expect data-driven priming to be affected. This appears to be the case. When attention at encoding is manipulated with a task that also decreases identification levels, the level of priming in a perceptual identification task is also reduced (Hawley \&
Johnston, 1991). Although further research is needed, this analysis may help resolve conflicting reports concerning the influence of attention on indirect memory performance.

\section{Implications and Conclusions}

The results of the current study have implications for processing views of amnesia and cognitive aging. With respect to the former, several researchers have noted the similarity in memory performance between amnesic patients and healthy subjects placed under divided attention or nonsemantic encoding conditions (Cermak, 1993; Graf, Mandler, \& Haden, 1982; Jacoby et al., 1989). Both of these subject groups often show intact priming accompanied by markedly reduced levels of performance on direct memory tests compared with healthy subjects under full-attention or semantic-encoding conditions (see Roediger \& McDermott, 1993; Shimamura, 1986, 1993, for reviews). This has led to the suggestion that an attentional deficit may underlie amnesic performance on direct memory tests. Specifically, it has been hypothesized that this patient population may be less able than healthy subjects to carry out attention-demanding elaborative processing (Cermak, 1993; Graf et al., 1982; Jacoby et al., 1989).

Contrary to this view, a recent review of theories of amnesia suggests that reduced elaborative encoding is not a general characteristic of amnesia (Shimamura, 1991). The data from the present study are also inconsistent with this view, when taken in conjunction with results from the amnesic literature. First, in experiments quite similar to Experiment 1, amnesics have shown normal levels of priming in the category-exemplar production task (Blaxton, 1992, Experiment 3, random condition; Graf et al., 1985). Healthy subjects placed in divided-attention encoding conditions (as in Experiment 1), however, show reduced priming on the same task. In fact, they show no priming at all. In addition, Srinivas and Roediger (1990) showed that nonsemantic encoding instructions decrease priming, relative to semantic encoding instructions, in a variant of the category-exemplar production task. These results, along with the current data, indicate that for conceptually driven priming tasks, decreased attention or elaboration at encoding does not provide an analog for anterograde amnesia.

A similar point can be made concerning views of cognitive aging. Like healthy young adults placed under divided-attention or nonsemantic encoding conditions, older adults have generally shown intact (or nearly intact) priming but reduced memory on direct tests (see Light \& La Voie, 1993, and Mitchell, 1993, for recent reviews). These findings are consistent with other evidence that age-related decrements in memory are the result of reduced attentional resources or controlled processing (Craik, 1994; Craik \& Byrd, 1982; Hasher \& Zacks, 1979; Jennings \& Jacoby, 1993). This conclusion has been further bolstered by studies of divided attention in nonmemory tasks (McDowd \& Craik, 1988; Salthouse, 
Rogan, \& Prill, 1984) and recent work using measures of working memory (Salthouse, 1987; Salthouse \& Mitchell, 1989; Salthouse, Mitchell, \& Palmon, 1989; Salthouse, Mitchell, Skovronek, \& Babcock, 1989).

Despite these findings, however, the current data conflict with the hypothesis that a decrease in attentiondependent processing produces the memory loss observed in older adults. Because of the demonstrated dependence of the category-exemplar production test on the availability of attentional resources (Experiment 1), one might predict that older adults would show impairments on this test. Nevertheless, no age differences have been found (Light \& Albertson, 1989). In other words, younger adults with reduced attentional capability, but not older adults, are impaired on this priming task. It seems, then, that for normal aging, as well as for amnesia, limited attention does not account for the pattern of performance across memory tests.

\section{REFERENCES}

Baddeley, A., Lewis, V., Eldridge, M., \& Thompson, N. (1984). Attention and retrieval from long-term memory. Journal of Experimental Psychology: General, 113, 518-540.

Battig, W. F., \& Montague, W. E. (1969). Category norms for verbal items in 56 categories: A replication and extension of the Connecticut category norms. Journal of Experimental Psychology Monographs, $\mathbf{8 0}$ (3, Pt. 2).

Besson, M., Fischler, I., Boaz, T., \& Raney, G. (1992). Effects of automatic associative activation on explicit and implicit memory tests. Journal of Experimental Psychology: Learning, Memory, \& Cognition, 18, 89-105.

BLAXTON, T. A. (1989). Investigating dissociations among memory measures: Support for a transfer-appropriate processing framework Journal of Experimental Psychology: Learning, Memory, \& Cognition, 15, 657-668.

Blaxton, T. A. (1992). Dissociations among memory measures in memory-impaired subjects: Evidence for a processing account of memory. Memory \& Cognition, 20, 549-562.

Bornstein, R. F., Leone, D. R., \& Galley, D. J. (1987). The generalizability of subliminal mere exposure effects: Influences of stimuli perceived without awareness. Journal of Personality \& Social Psychology, 53, 1070-1079.

CERMAK, L. S. (1993). Automatic versus controlled processing and the implicit task performance of amnesic patients. In P. Graf \& M. E. J Masson (Eds.), Implicit memory: New directions in cognition, development, and neuropsychology (pp. 287-301). Hillsdale, NJ: Erlbaum

Challis, B. H., \& BRodBeCK, D. R. (1992). Levels of processing affects priming in word fragment completion. Journal of Experimental Psychology: Learning, Memory, \& Cognition, 18, 595-607.

Cherry, C. (1953). Some experiments on the recognition of speech with one and with two ears. Journal of the Acoustical Society of America, 25, 975-979.

CRAIK, F. I. M. (1982). Selective changes in encoding as a function of reduced processing capacity. In F. Klix, J. Hoffman, \& E. van der Meer (Eds.), Cognitive research in psychology (pp. 152-161). Amsterdam: North-Holland.

CRAIK, F. I. M. (1983). On the transfer of information from temporary to permanent memory. Philosophical Transactions of the Royal Society: Series $B, \mathbf{3 0 2}, 341-359$.

Craik, F. I. M. (1994). Memory changes in normal aging. Current Directions in Psychological Science, 3, 155-158.

CraIK, F. I. M., \& BYrd, M. (1982). Aging and cognitive deficits: The role of attentional resources. In F. I. M. Craik \& S. E. Trehub (Eds.), Aging and cognitive processes (pp. 191-211). New York: Plenum.

Craik, F. I. M., Moscovitch, M., \& McDowd, J. M. (1994). Contributions of surface and conceptual information to performance on implicit and explicit memory tasks. Journal of Experimental Psychology: Learning, Memory, \& Cognition, 20, 864-875.

EICH, E. (1984). Memory for unattended events: Remembering with and without awareness. Memory \& Cognition, 12, 105-111.

Fisk, A. D., \& SCHNEIDER, W. (1984). Memory as a function of attention, level of processing, and automatization. Journal of Experimental Psychology: Learning, Memory, \& Cognition, 10, 181-197.

Gabrieli, J. D. E., Stone, M. V., Shackleton, K., Thompson-Schill, S. L., LADD, S. L., VAIDYa, C. J., \& ChARI, A. (1995). Attention and implicit memory for words. Manuscript submitted for publication. Gellatly, A., Parker, A., Blurton, A., \& Woods, C. (1994). Word stem and word fragment completion following semantic activation and elaboration. Journal of Experimental Psychology: Learning. Memory, \& Cognition, 20, 1099-1107.

GRAF, P., \& MANDLER, G. (1984). Activation makes words more accessible, but not necessarily more retrievable. Journal of Verbal Learning \& Verbal Behavior, 23, 553-568.

Graf, P., Mandler, G., \& Haden, P. (1982). Simulating amnesic symptoms in normal subjects. Science, 218, 1243-1244.

Graf, P., Shimamura, A., \& Squire, L. (1985). Priming across modalities and priming across category levels: Extending the domain of preserved functions in amnesia. Journal of Experimental Psychology: Learning, Memory, \& Cognition, 11, 386-396.

Hamman, S. B. (1990). Level-of-processing effects in conceptually driven implicit tasks. Journal of Experimental Psychology: Learning, Memory, \& Cognition, 16,970-977.

HASHER, L., \& ZACKS, R. T. (1979). Automatic and effortful processes in memory. Journal of Experimental Psychology: General, 108, 356-386.

HAWLEY, K. J., \& JoHNSTON, W. A. (1991). Long-term perceptual memory for briefly exposed words as a function of awareness and attention. Journal of Experimental Psychology: Human Perception \& Performance, 17, 807-815.

HaYman, C. A. G., \& JaCOBY, L. L. (1989). Specific word transfer as a measure of processing in the word-superiority paradigm. Memory \& Cognition, 17, 125-133.

JACOBY, L. L. (1983). Remembering the data: Analyzing interactive processes in reading. Journal of Verbal Learning \& Verbal Behavior, 22, 485-508.

JACOBY, L. L. (1991). A process dissociation framework: Separating automatic from intentional uses of memory. Journal of Memory \& Language, 30, 513-541.

JACOBY, L. L., \& BROOKS, L. R. (1984). Nonanalytic cognition: Memory, perception, and concept learning. In G. H. Bower (Ed.), The psychology of learning and motivation (Vol. 18, pp. 1-43). New York: Academic Press.

JACOBY, L. L., \& DALlaS, M. (1981). On the relationship between autobiographical memory and perceptual learning. Journal of Experimental Psychology: General, 110, 306-340.

JACOBY, L. L., Toth, J. P., \& Yonelinas, A. P. (1993). Separating conscious and unconscious influences of memory: Measuring recollection. Journal of Experimental Psychology: General, 122, 139-154.

JACOBY, L. L., WoloshyN, V., \& KelLeY, C. (1989). Becoming famous without being recognized: Unconscious influences of memory produced by divided attention. Journal of Experimental Psychology: General, 118, 115-125.

Jelicic, M., Bonke, B., Wolters, G., \& Phaf, R. H. (1992). Implicit memory for words presented during anaesthesia. European Journal of Cognitive Psychology, 4, 71-80.

JenNingS, J. M., \& JaCOBY, L. L. (1993). Automatic versus intentional uses of memory: Aging, attention, and control. Psychology \& Aging, 8, 283-293.

Koriat, A., \& Feuerstein, N. (1976). The recovery of incidentally acquired information. Acta Psychologica, 40, 463-474

KUNST-Wilson, W. R., \& ZAJONC, R. B. (1980). Affective discrimination of stimuli that cannot be recognized. Science, 207, 557-558.

LA VoIE, D., \& LIGHT, L. L. (1994). Adult age differences in repetition priming: A meta-analysis. Psychology \& Aging, 9, 539-553.

Light, L. L., \& Albertson, S. A. (1989). Direct and indirect tests of memory for category exemplars in young and older adults. Psychology \& Aging, 4, 487-492. 
Light, L. L., \& LA VOIE, D. (1993). Direct and indirect measures of memory in old age. In P. Graf \& M. E. J. Masson (Eds.), Implicit memory: New directions in cognition, development, and neuropsychology (pp. 207-230). Hillsdale, NJ: Erlbaum.

MacKaY, D. G. (1973). Aspects of the theory of comprehension, memory and attention. Quarterly Journal of Experimental Psychology, $25,22-40$.

Mandler, G., Nakamura, Y., \& Van Zandt, B. J. S. (1987). Nonspecific effects of exposure on stimuli that cannot be recognized. Journal of Experimental Psychology: Learning, Memory, \& Cognition, 13, 646-648.

MCDowd, J. M., \& CraIK, F. I. M. (1988). Effects of aging and task difficulty on divided attention performance. Journal of Experimental Psychology: Human Perception \& Performance, 14, 267-280.

Merickle, P., \& ReINGOLD, E. (1991). Comparing direct (explicit) and indirect (implicit) measures to study unconscious memory. Journal of Experimental Psychology: Learning, Memory, \& Cognition, 17, 224-233.

MitCheLl, D. B. (1993). Implicit and explicit memory for pictures: Multiple views across the lifespan. In P. Graf \& M. E. J. Masson (Eds.), Implicit memory: New directions in cognition, development, and neuropsychology (pp. 171-191). Hillsdale, NJ: Erlbaum.

MORAY, N. (1959). Attention in dichotic listening: Affective cues and the influence of instructions. Quarterly Journal of Experimental Psy. chology, 11, 56-60.

Morris, C. D., Bransford, J. D., \& Franks, J. J. (1977). Levels of processing versus transfer appropriate processing. Journal of Verbal Learning \& Verbal Behavior, 16, 519-533.

Mulligan, N. W. (in press). Attention and implicit memory tests: The effects of varying attentional load on conceptual priming. Memory \& Cognition.

Mull.igan, N. W., \& HiRshman, E. (1995). Speed-accuracy tradeoffs and the dual process model of recognition memory. Journal of Memory \& Language, $34,1-18$

MuRdock, B. B. (1965). Effects of subsidiary task on short-term memory. British Journal of Psychology, 56, 413-419.

NEELY, J. H. (1989). Experimental dissociations and the episodic semantic memory distinction. In H. L. Roediger III \& F. I. M. Craik (Eds.), Varieties of memory and consciousness: Essays in honour of Endel Tulving (pp. 229-270). Hillsdale, NJ: Erlbaum

Norman, D. A. (1969). Memory while shadowing. Quarterly Journal of Experimental Psychology, 21, 85-93.

PARKIN, A. J., ReID, T. K., \& Russo, R. (1990). On the differential nature of implicit and explicit memory. Memory \& Cognition, 18, 507-514.

PARKIN, A. J., \& Russo, R. (1990). Implicit and explicit memory and the automatic/effortful distinction. European Journal of Cognitive Psychology, 2, 71-80.

RaJARAM, S., \& RoEDIGER, H. L., III (1993). Direct comparison of four implicit memory tests. Journal of Experimental Psychology: Learning, Memory, \& Cognition, 19, 765-776.

RAPPOLD, V. A., \& HASHTROUDI, S. (1991). Does organization improve priming? Journal of Experimental Psychology: Learning, Memory, \& Cognition, 17, 103-114.

RichaRDSON-KLAVEHN, A., \& BJoRK, R. A. (1988). Measures of memory. Annual Review of Psychology, 39, 475-543.

RichaRDSON-KLAVEHN, A., GARDINER, J. M., \& JaVA, R. I. (1994). Involuntary conscious memory and the method of opposition. Memory, 2, 1-29.

RoEDIGER, H. L., III (1990). Implicit memory: Retention without remembering. American Psychologist, 45, 1043-1056.

RoEdiger, H. L., III, \& Blaxton, T. A. (1987). Retrieval modes produce dissociations in memory for surface information. In D. Gorfein \& R. R. Hoffman (Eds.), Memory and cognitive processes: The Ebbinghaus Centennial Conference (pp. 349-379). Hillsdale, NJ: Erlbaum.

RoEDIGER, H. L., III, \& MCDERMotT, K. B. (1993). Implicit memory in normal human subjects. In F. Boller \& J. Grafman (Eds.), Handbook of neuropsychology (pp. 63-131). Amsterdam: Elsevier, NorthHolland.

Roediger, H. L., III, Weldon, M. S., \& Challis, B. H. (1989). Explaining dissociations between implicit and explicit memory: A processing account. In H. L. Roediger III \& F. I. M. Craik (Eds.), Varieties of memory and consciousness: Essays in honour of Endel Tulving (pp. 3-41). Hillsdale, NJ: Erlbaum.

Roediger, H. L., III, Weldon, M. S., Stadler, M. A., \& Riegler, G. H. (1992). Direct comparison of word stems and word fragments in implicit and explicit retention tests. Journal of Experimental Psychology: Learning, Memory, \& Cognition, 18, 1251-1264.

Russo, R., \& Parkin, A. J. (1993). Age differences in implicit memory: More apparent than real. Memory \& Cognition, 21, 73-80.

SAlthouse, T. A. (1987). Adult age differences in integrative spatial ability. Psychology \& Aging, 2, 254-260.

Salthouse, T. A., \& Mitchell, D. R. D. (1989). Structural and operational capacities in integrative spatial ability. Psychology \& Aging, 4, 18-25.

Salthouse, T. A., Mitchell, D. R. D., \& Palmon, R. (1989). Memory and age differences in spatial manipulation ability. Psychology \& Aging, 4, 480-486.

Salthouse, T. A., Mitchell, D. R. D., Skovronek, E., \& Babcock, R. L. (1989). Effects of adult age and working memory on reasoning and spatial abilities. Journal of Experimental Psychology. Learning, Memory, \& Cognition, 15, 507-516.

Salthouse, T. A., Rogan, J. D., \& Prill, K. (1984). Division of attention: Age differences on a visually presented memory task. Memory \& Cognition, 12, 613-620.

SCHACTER, D. L. (1987). Implicit memory: History and current status. Journal of Experimental Psychology: Learning, Memory, \& Cognition, 13, 501-518.

SCHACTER, D. L. (1992), Priming and multiple memory systems: Perceptual mechanisms of implicit memory. Journal of Cognitive Neuroscience, 4, 244-256.

SCHACTER, D. L., Bowers, J., \& BoOKeR, J. (1989). Intention, awareness, and implicit memory: The retrieval intentionality criterion. In S. Lewandowsky, J. C. Dunn, \& K. Kirsner (Eds.), Implicit memory: Theoretical issues (pp. 47-65). Hillsdale, NJ: Erlbaum.

Seamon, J., Brody, N., \& KaUfF, D. M. (1983). Affective discrimination of stimuli that are not recognized: Effects of shadowing, masking, and cerebral laterality. Journal of Experimental Psychology: Learning, Memory, \& Cognition, 9, 544-555.

SeAmon, J., Marsh, R., \& BRODY, N. (1984). Critical importance of exposure duration for attentive discrimination of stimuli that are not recognized. Journal of Experimental Psychology: Learning, Memory, \& Cognition, 10, 465-469.

Shimamura, A. P. (1986). Priming effects in amnesia: Evidence for a dissociable memory function. Quarterly Journal of Experimental Psychology, 38A, 619-644.

ShimamuRA, A. P. (1991). Disorders of memory: The cognitive science perspective. In F. Boller \& J. Grafman (Eds.), Handbook of neuropsychology (pp. 35-73). New York: Elsevier.

Shimamura, A. P. (1993). Neuropsychological analysis of implicit memory: History, methodology and theoretical interpretations. In P. Graf \& M. E. J. Masson (Eds.), Implicit memory: New directions in cognition, development, and neuropsychology (pp. 265-285). Hillsdale, NJ: Erlbaum

Smith, M. E., \& OsCar-Berman, M. (1990). Repetition priming of words and pseudowords in divided attention and in amnesia. Journal of Experimental Psychology: Learning, Memory, \& Cognition, 16, 1033-1042.

SQUIRE, L. R. (1992). Memory and the hippocampus: A synthesis from findings with rats, monkeys, and humans. Psychological Review, 99, 195-231.

SRINIVAS, K., \& RoEdiger, H. L., III (1990). Classifying implicit memory tests: Category association and anagram solution. Journal of Memory \& Language, 29, 389-412.

WELDON, M. S. (1991). Mechanisms underlying priming on perceptual tests. Journal of Experimental Psychology: Learning, Memory, \& Cognition, 17, 526-541.

\section{NOTES}

1. In this paper, we use the generic term priming rather than a more specific term such as repetition priming. The terminology of the field 
is still in flux, and different researchers define the more specific terms differently (see, e.g., Roediger \& McDermott, 1993, and La Voie \& Light, 1994, for different definitions of repetition priming). However, there seems to be fair agreement that the term priming denotes enhanced performance for previously presented information on an indirect memory test. See Roediger and McDermott (1993, pp. 65-66) for a discussion of terminological issues.

2. It is important to distinguish automatic encoding processes from automatic retrieval processes. Some researchers have proposed that automaticity during retrieval, as well as encoding, is central to performance on indirect memory tests (e.g., Jacoby, 1991; Jacoby et al., 1989). In the present study, we limit our investigation to the role of automatic encoding processes.

3. We have recently obtained further evidence against the intentionalretrieval account for this conceptually driven task (Mulligan, in press). In this study, attention was manipulated over several levels (e.g., full attention, mildly divided attention, strongly divided attention). The results indicate that mild division of attention affects only category-cued recall, but that strong divisions of attention affect both category-cued recall and category-exemplar production. The results of the full and strongly divided attention conditions replicate the results of the present study. In addition, these results are inconsistent with an intentionalretrieval account. Had subjects in the category-exemplar production task been using intentional retrieval, we would expect lower performance for all levels of divided attention, as was seen in the direct test of category-cued recall.

4. The TAP view suggests that indirect tests that show the effects of divided attention lie closer to the middle of the data-driven versus conceptually driven continuum than those that do not show such effects (see, e.g., Srinivas \& Roediger, 1990). We again note that not all of the relevant memory tests have been classified as data driven according to criteria of the TAP framework.

5. Gabrieli et al. (1995) have recently found very similar results.

(Manuscript received December 20, 1994; revision accepted for publication August 7, 1995.) 